\title{
High resolution mapping of urban areas using SPOT-5 images and ancillary data
}

\author{
Elif Sertel $^{1 *}$, Semih Sami Akay ${ }^{2}$ \\ ${ }^{1}$ Istanbul Technical University, Department of Geomatics Engineering, 34669, ISTANBUL-TR \\ ${ }^{2}$ Istanbul Technical University, Center for Satellite Communication and Remote Sensing, 34669, ISTANBUL-TR
}

\begin{abstract}
This research aims to propose new rule sets to be used for object based classification of SPOT-5 images to accurately create detailed urban land cover/use maps. In addition to SPOT-5 satellite images, Normalized Difference Vegetation Index (NDVI) and Normalized Difference Water Index (NDWI) maps, cadastral maps, Openstreet maps, road maps and Land Cover maps, were also integrated into classification to increase the accuracy of resulting maps. Gaziantep city, one of the highly populated cities of Turkey with different landscape patterns was selected as the study area. Different rule sets involving spectral, spatial and geometric characteristics were developed to be used for object based classification of $2.5 \mathrm{~m}$ resolution Spot-5 satellite images to automatically create urban map of the region. Twenty different land cover/use classes obtained from European Urban Atlas project were applied and an automatic classification approach was suggested for high resolution urban map creation and updating. Integration of different types of data into the classification decision tree increased the performance and accuracy of the suggested approach. The accuracy assessment results illustrated that with the usage of newly proposed rule set algorithms in object-based classification, urban areas represented with seventeen different sub-classes could be mapped with $94 \%$ or higher overall accuracy.
\end{abstract}

Keywords: Urban mapping, remote sensing, SPOT-5, object-based classification

\section{Introduction}

The majority part of the world population has been living in urban areas and this number has been steadily increasing. Similar to several cities in the world, majority of the cities in Turkey have been experiencing controlled or uncontrolled expansion of urban areas as a result of development of transportation infrastructures, industrial areas, settlements and other built-up areas (Akay, 2014; Seifert, 2009). Rural migration to big cities and population growth are the main reason for urbanization. Urbanization has significant impact on the environment like causing modification of landscape, air pollution, temperature increase etc.
Identification and quantification of urban areas and having information about the rate and trends of urban growth provide beneficial inputs for urban and regional planners (Thapa and Murayama, 2009). Urban landscapes are variable in space and time; therefore, high resolution multi-temporal satellite images are important data source for spatiotemporal analyses of urban landscapes. There have been several efforts on deriving urban information and monitoring urban areas using remotely sensed data and details of remote sensing based urban monitoring for Europe could be found in Seifert, 2009. Comprehensive knowledge about landscape characteristics of urban areas is crucial for the future development and effective management of these areas (Deng et al., 2009). Remote sensing is one of the fastest and most preferred methods of producing information 
about the land use/cover of cities and countries. High resolution satellite images are extremely useful to be used for spatiotemporal monitoring of cities, planning and development plans and decision support for city managers and planners. Fast, accurate, cost and time effective map production and urban planning projects could be successfully employed using remote sensing technologies (Seifert, 2009; Deng et al., 2009; Blaschke et al., 2011; Sertel et al., 2008).

The European Urban Atlas is one of the latest initiatives in Europe, a land monitoring service as a component of GMES (Global Monitoring for Environment and Security) / Copernicus program, to create reliable high resolution land use maps of Large Urban Zones (LUZ, having population of 100,000 or more) to monitor and manage urban areas. Main data source for the land use map production is high resolution satellite images ( $2.5 \mathrm{~m}$ or better) in addition to several ancillary data like COTS (Commercial off-the-shelf), FTS (Fast Track Service), topographic map etc. Urban Atlas includes 22 urban classes (artificial surfaces) in four hierarchical levels and four non-urban classes. The scale of Urban Atlas is 1:10,000 and the minimum mapping unit (MMU) is 0.25 ha for the artificial surfaces but in some exceptional cases this could be $500 \mathrm{~m}^{2}$ and MMU is 1 ha for the other surfaces (EEA(European Environment Agency)) (Urban Atlas Final Report, 2009). Urban Atlas database is aiming to provide homogeneous and up-to-date spatial information on urban environments, allowing intercomparison of different European cities (Ludlow and Steinborn, 2009).

Scale, application area, source data and types of users should be considered during the selection of classification scheme for land use/cover mapping. In this research, we used classification scheme of Urban Atlas project which is mutually exclusive, exhaustive and hierarchical and including classes like urban areas with different densities, industrial, commercial, public, military and private units, roads, railways, ports etc. These classes will be very functional and supportive for different level of users from decision makers and planners to public. In addition, urban land cover/use classes applied in this research could be used for various mapping, urban and regional planning applications such as mapping and monitoring urban changes, urban growth and land use dynamics, urban infrastructure characterization, urban road mapping, urban functions analysis, environmental and resources management, infrastructure and transportation planning and development (Seifert, 2009; Ludlow and Steinborn, 2009; Weng, 2012).

Considering the complexity of the urban landscape due to high spatial and spectral variations in urban surface materials, accurate mapping of urban areas is a challenging task (Blaschke et al., 2011; Herold et al., 2003; Weng, 2012; Mohapatra, and $\mathrm{Wu}, 2011$; Lu, and Weng, 2006). Impervious land cover have similar spectral properties especially when only limited number of bands were used; therefore, inclusion of spatial and texture information into urban area classification is necessary (Salehi; 2012) Different researchers have applied various approaches to improve urban land use/cover accuracy with the inclusion of geographic data, textural features, contextual information, expert systems and fuzzy classification (Thapa and Murayama, 2009; Deng et al., 2009; Weng, 2012; Mohapatra, and $\mathrm{Wu}, 2011 ; \mathrm{Lu}$, and Weng, 2006; City Development Information. , 2014; Gamba et al., 2005; Matikainen and Karila, 2011). The importance of different requirements for spatial, spectral and temporal resolution and geometric characteristics of urban features to map impervious surfaces in the urban areas using remotely sensed data was emphasized (Herold et al., 2003). However, most of these researches conducted with high resolution satellite images were either applied to a few number of urban classes or to a small region compared to real size of a city.

This research aims to create an accurate and upto-date urban land use/cover map of Gaziantep city (total area of $6,558 \mathrm{~km}^{2}$ ), Turkey by developing rule based decision trees including spectral, geometric and spatial characteristics to be used for object-oriented classification of high resolution satellite images with the integration of different thematic layers to automate urban mapping procedure. Twentytwo different land cover/use classes (19 of them related to urban and artificial surfaces) were produced by applying the proposed approach 
with an overall accuracy of $95.46 \%$ and kappa value of 0.932 .

\section{Study Area}

Gaziantep is one of the world's oldest residential areas and it is center of culture and commerce with historic Silk Road. Being an important gateway, Gaziantep's location is within the southeast part of the Mediterranean region (Figure 1). Gaziantep is one of the oldest cities in the world having continuous inhabitation. Gaziantep is an important economic center of Turkey with several large industrial businesses and the largest organized industrial area of the country. Industrial and economic developments have resulted in expansion in residential and industrial areas of the city (City Population; 2014).

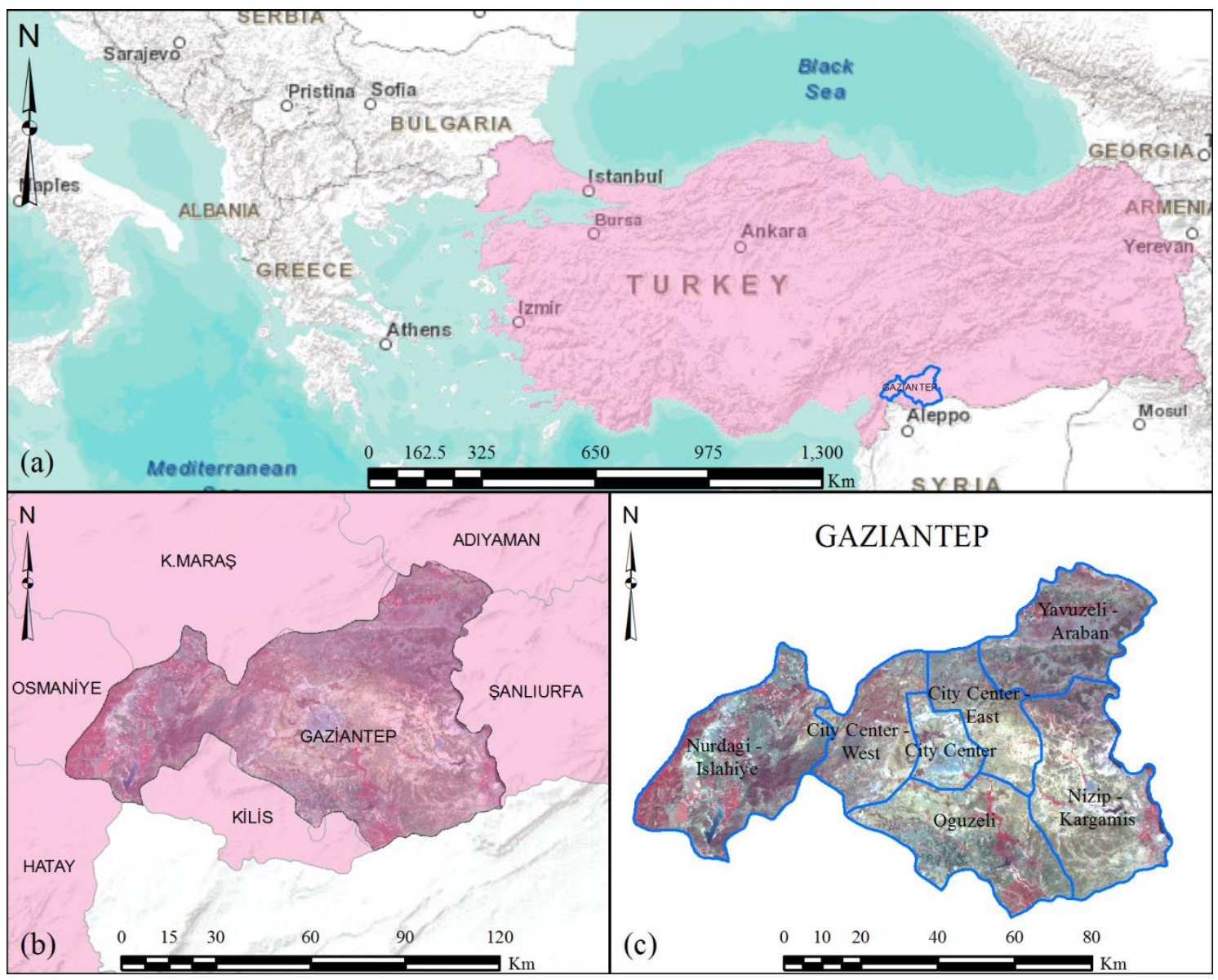

Fig. 1 Location of the study area (a) Turkey's location (b) Gaziantep (c) 7 regions of Gaziantep

Gaziantep, with its investments in varied sectors like industry, commerce and tourism, has risen to the forefront of Turkey's developing cities. The population of the city of Gaziantep has been increasing as a result development of the regional economy due to investments, and influence of immigration. With a population of over $1,000,000$, it is the 8th largest city in Turkey. The population of Gaziantep has experienced an annual growth of 50,000 per year, with the numbers counting of $1,700,763$ in $2010 ; 1,753,596$ in 2011 and $1,799,558$ in 2012 (Akay, 2014). Parallel to the rising population, the rapid spread of residential and industrial areas has been observed. 


\section{Data}

Six SPOT-5 images obtained in 1, 6 and 8 of August 2013 were used as primary earth observation data for this research and treated as primary data source for the delineation of different land cover/use classes. Land cover/use classes used in this research are adapted from Urban Atlas project nomenclature that is given in the Figure 2. There are four different hierarchical levels in the classification scheme. Urban fabric is divided into continuous (code 11100) and discontinuous (code 11200) in the third level whereas discontinuous urban fabric divided into four classes (codes 11210-11240) based on the soil sealing value in the fourth level. Road and rail network and associated land class (code 12200) in the third level is divided into three sub-classes in the fourth level namely fast transit roads and associated lands (code 12210), other roads and associated lands (code 12220) and railways and associated lands (code 12230). Detailed information regarding to explanation of each class could be found in Myint et al., 2011 and Seifert, 2009)

\section{Legend}

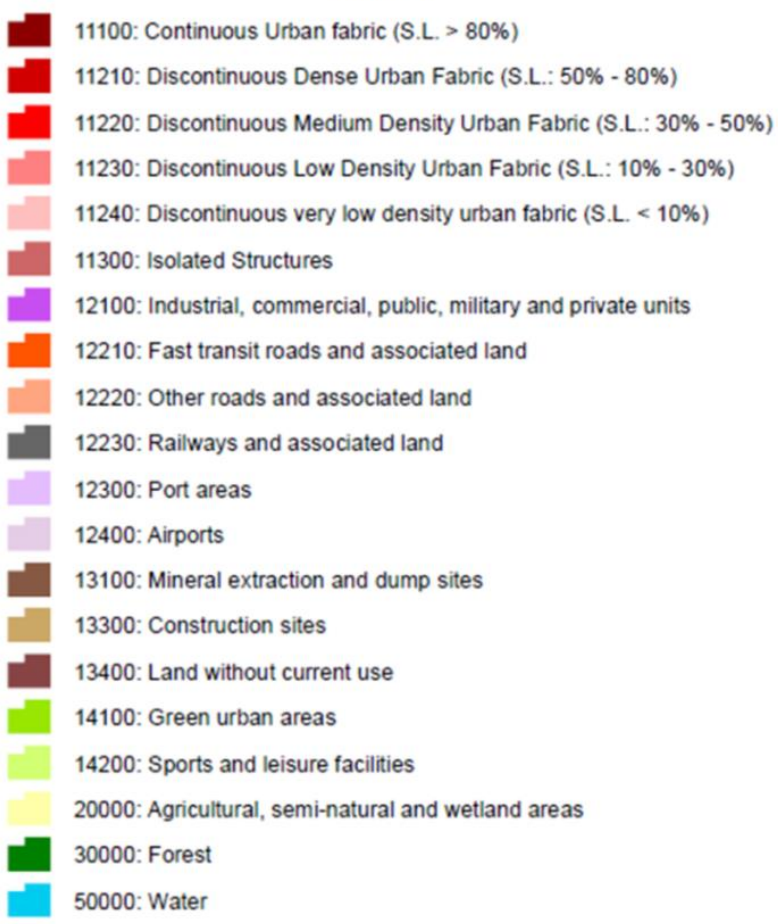

Fig. 2 Land use/cover classes used in the study

Multi-temporal Landsat- 8 images obtained on 18th of June, 20th of July and 21st of August 2013 were used to create Normalized Difference Vegetation Index (NDVI) maps. This multi-temporal NDVI data set was used to determine general boundaries of forest and vegetated areas visually and to collect training sites.

In addition to satellite images, 1:1,000 scale master zoning maps of central locations were also used. Point of interests like schools, cemeteries, public buildings are available in this map as attribute; therefore, this information was used for the determination of some fourth level urban classes used in this study like industrial, commercial, public, military and private units.

Forest type maps, Open Street Map road data, CORINE map, online maps that provides visual information and features about locational 
objects (Google Earth, Yandex, Bingmaps etc.) were also used in this study. Forest Type maps and online maps were used to aid interpretation procedure for training site selection. Moreover, these online maps were also used to find out land use information of industrial, residential areas and road types.

Soil Sealing Layer based on Fast Track Service specifications was created from SPOT 5 NDVI imagery for the determination of fourth level discontinuous urban classes based on different soil sealing values (code 11210-11240).

All of the mentioned data sets were also used for the accuracy assessment after conducting classification.

\section{Methods}

\section{Geometric Correction}

Geometric accuracy and scale of land use maps to be used for urban studies are out most important, therefore spatial resolution selection and geometric correction procedures should be carefully conducted prior to further analysis of satellite images. As an example, satellite images having spatial resolution of $2.5 \mathrm{~m}$ or better, with $5 \mathrm{~m}$ positional accuracy are required to be used in European Urban Atlas project which has the scale of $1: 10,000$.

In our research, SPOT-5 images with $2.5 \mathrm{~m}$ resolution were orthorectified to remove geometric distortions of images and make them compatible to be used with other geographic data sets and conduct absolute measurements. Orthorectified image of city center were compared with 1:1000 scale maps to check their locational accuracy. Coordinates of 20 control points were read from orthorectified imagery and these values were compared with the coordinates obtained from 1:1000 scale map with higher positional accuracy, to find out the final geometric accuracy of orthorectified SPOT-5 images. Comparison analysis illustrated that RMSE of control points were generally between 1 and $3.5 \mathrm{~m}$ and extreme maximum RMSE of $4 \mathrm{~m}$ was obtained only for few control points. It was concluded that locational accuracy of SPOT-5 images used in this research have $5 \mathrm{~m}$ or better accuracy and compatible to create high resolution urban map which was also inferred from Urban Atlas project. After the orthorectification of each SPOT-5 images, all of the six images were mosaicked to create a complete image-map of Gaziantep city.

\section{Classification}

High $(>1 \mathrm{~m}$ and $<2.5 \mathrm{~m})$ and very high resolution $(\leq 1 \mathrm{~m}) \quad(\mathrm{HR}$ and VHR) satellite images such as, SPOT-5, SPOT-6, IKONOS, Worldview, Pleiades could be used for the classification of urban land use/cover classes. Introducing HR and VHR satellite images into urban mapping lead higher levels of detailed features; however, having higher spatial details exhibit complicated spectral characteristics due to the fact that very small objects could be mapped. Traditional pixel-based image classification methods rely on spectral characteristics and do not count for spatial, topological and textural features; therefore, these methods fail to create highly accurate urban land cover/use maps from HR and VHR images since urban classes in these images pose complex spectral characteristics. These problems could be overcome using objectbased classification techniques which do not only deal with spectral information but also spatial, textural and hierarchical features after segmentation of imagery (Salehi et al., 2012; Walker, and T. Blaschke, 2008; Campbell, 2007; eCognition, eCognition Developer, 2010; Lobo, 1997).

Object-based classification approach includes two step namely segmentation and classification. In order to obtain accurate results and conduct fast classification, Gaziantep city was divided into seven sub-regions (Figure 1(c)). These seven sub-region areas include one city center region and six rural regions, and each of them classified separately. In the segmentation stage, image pixels were grouped into segments based on shape, color, texture characteristics and spatial relationships. Scale parameter is used for the creation of different size objects. Bigger objects could be obtained using bigger scale parameters and small objects could be obtained using smaller scale parameters for a constant spatial resolution. Color parameter is affected by the spectral characteristics of the objects. 
In the classification stage, objects in the images are assigned to land use/cover classes with the spectral reflectance of the earth objects, patterns, depending on objects' location and other features' parameters. In addition, thematic layers can also be used as ancillary data that allows the assignment of objects in the classification process. Table 1 shows thematic data used in segmentation and classification process with respect to regions and classes.

Master Zoning Maps $(1: 1,000)$ acquired from Gaziantep Municipality was only available for city center of the city (Region 7). For that reason, segmentation/classification process of this region differs from other 6 regions. It ensured good delineation of land parcels and roads. Furthermore, it was also used to assign all artificial surface classes. Urban sub-classes were classified with FTS data. Corine data was used to assign forest class by code number in the thematic layer. OpenStreetMap road data was used in the segmentation process which resulted better delineation of roads.

Table 1 Thematic Layers used in segmentation/classification process

\begin{tabular}{|l|l|l|}
\hline Thematic Layer & Region & Purpose \\
\hline Master Zoning Maps & $\begin{array}{l}\text { Region 7 (city } \\
\text { center) }\end{array}$ & $\begin{array}{l}\text { Segmentation/Classification of Artificial Surfaces } \\
\text { (1xxx) }\end{array}$ \\
\hline FTS (SPOT 5 NDVI) & All regions & Classification of 11000 \\
\hline Corine 2006 & Regions 1 to 6 & Classification of 30000 \\
\hline $\begin{array}{l}\text { OpenStreetMap Road } \\
\text { Data }\end{array}$ & Regions 1 to 6 & Segmentation \\
\hline
\end{tabular}

Table 2 Segmentation parameters for sub-regions

\begin{tabular}{|l|l|l|l|l|}
\hline Sub-region no & Sub-region name & Scale & Shape & Compactness \\
\hline 1 & Nizip-Kargamis & 65 & 0.7 & 0.5 \\
\hline 2 & Nurdagi-Islahiye & 70 & 0.6 & 0.5 \\
\hline 3 & Oguzeli & 60 & 0.7 & 0.5 \\
\hline 4 & City center-west & 65 & 0.8 & 0.5 \\
\hline 5 & City center-east & 70 & 0.6 & 0.5 \\
\hline 6 & Yavuzeli-Araban & 60 & 0.7 & 0.5 \\
\hline 7 & City center & 75 & 0.7 & 0.5 \\
\hline
\end{tabular}

Different segmentation parameters were applied to seven sub-regions of the research area to find out the best combinations for the segment identification of the related sub-region. Scale, shape and compactness of different sub-regions were presented in Table 2.

Figure 3 shows an example of segmentation results for Region 7 (city center) which conducted by incorporating master zoning maps into segmentation procedure resulting in detailed determination of roads.

After the segmentation, several indices and functions were used to extract different land use/cover classes. Table 3 explains features and indices used in classification process. Figure 4 summarizes how these indices and functions used in the object based classification.

For 6 rural regions of Gaziantep city, Normalized Difference Water Index (NDWI) was used to identify water and non-water areas. Different thresholds were applied to find out an appropriate threshold value to identify water areas (code 50000) using SPOT-5 data. Based on analysis of different segments representing water class, NDWI value of 0.15 was found as a threshold to identify water bodies. Therefore, segments having NDWI value of 0.15 or higher were assigned to water class. 


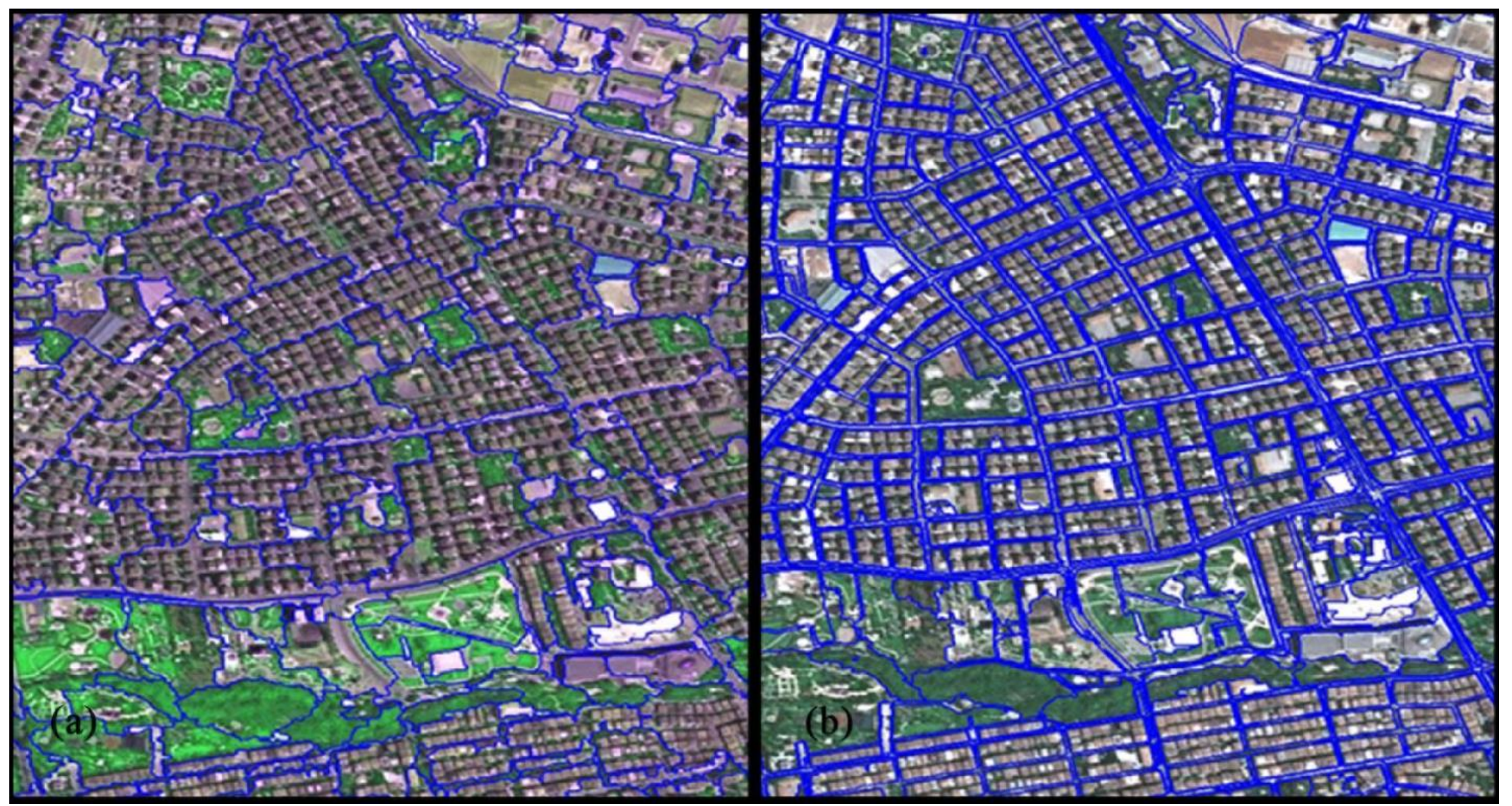

Fig. 3 Thematic layer (master zoning map) integration into segmentation for Region 7 (a) segmentation without master zoning maps (b) segmentation with master zoning maps 
Table 3 Indices and functions used in the research [adopted from Thomas et al., 2003]

\begin{tabular}{|c|c|}
\hline \multicolumn{2}{|c|}{ Measures of Spectral Response } \\
\hline $\begin{array}{l}\text { Standard deviation of } \\
\text { band } 4\end{array}$ & $\begin{array}{l}\text { The standard deviation of the NIR band derived from intensity values of } \\
\text { all pixels in this channel. }\end{array}$ \\
\hline Mean value of band 4 & Mean intensity values in the NIR band. \\
\hline Brightness & Mean of the brightness values in an image. \\
\hline NDVI & $\begin{array}{l}\text { Normalized difference vegetation index; NDVI }=(\mathrm{NIR}-\mathrm{RED}) /(\mathrm{NIR} \\
+\mathrm{RED})\end{array}$ \\
\hline NDWI & $\begin{array}{l}\text { Normalized difference water index; NDWI }=(\text { GREEN }- \text { NIR }) / \\
(\text { GREEN + NIR })\end{array}$ \\
\hline \multicolumn{2}{|l|}{ Measures of Shape } \\
\hline Shape index & Smoothness of the border of the image object. \\
\hline Border length & The sum of the edges of an image segment. \\
\hline Asymmetry & Length of an image object, in comparison to a regular polygon. \\
\hline Elliptic fit & Measures the similarity of object's shape to an ellipse. \\
\hline Area & The total number of pixels in the object \\
\hline \multicolumn{2}{|l|}{ Measures of Relation } \\
\hline $\begin{array}{l}\text { Relations To } \\
\text { Neighbor Objects }\end{array}$ & $\begin{array}{l}\text { Determines the relation of objects with various parameters to a given } \\
\text { class. }\end{array}$ \\
\hline
\end{tabular}

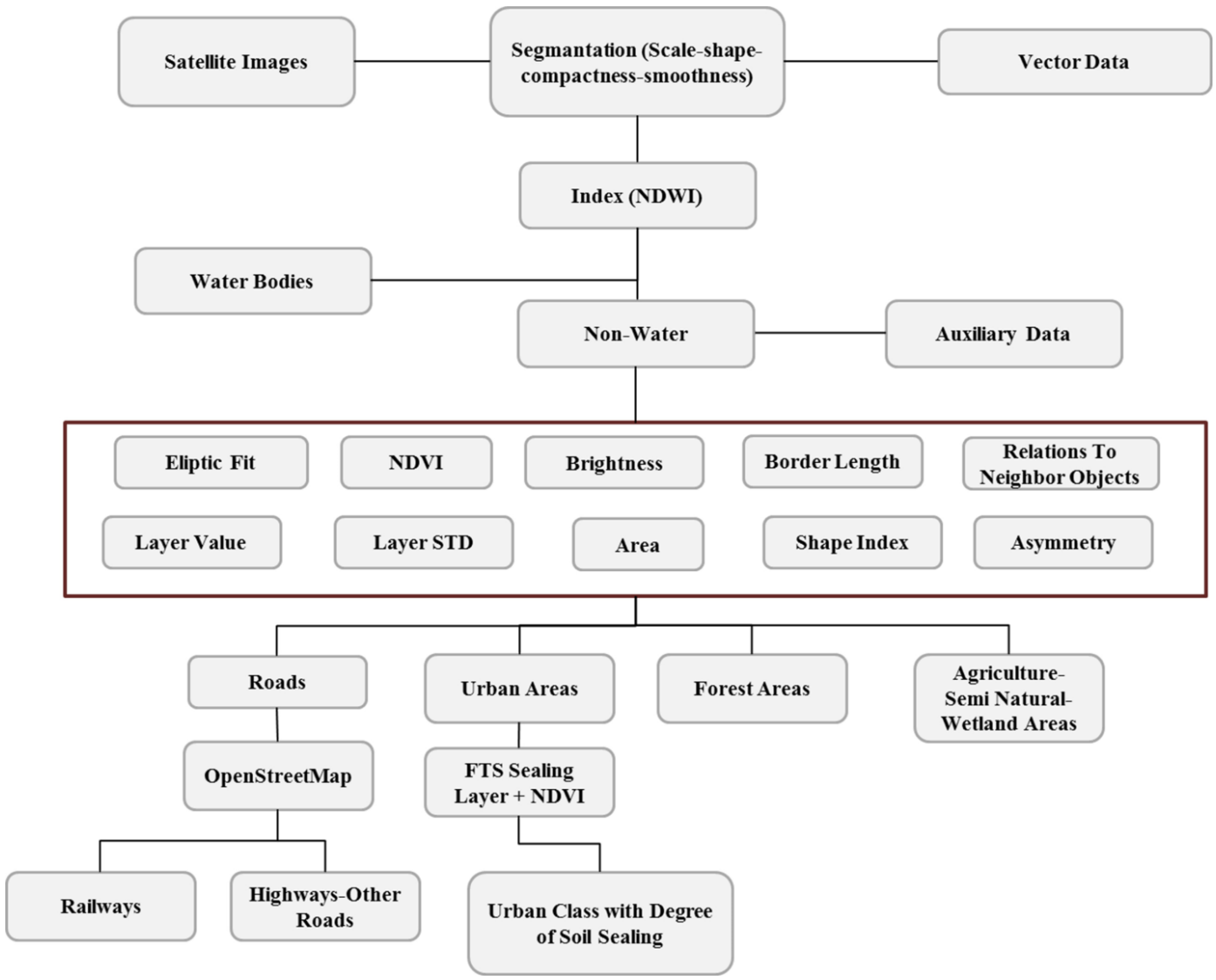

Fig. 4 Indices and functions used in object-based classification. 
Multi-temporal Normalized Difference Vegetation Index (NDVI) images created from Landsat images and forest type maps obtained from Ministry of Forestry were incorporated into the classification procedure for the selection of training sites to be used in objectbased nearest neighbour classification to identify forest and semi natural areas (code 30000). For different forest types, different NDVI ranges were determined based on the training sites. Railroads and highways in vector format obtained from Open Streetmaps were integrated into the segmentation procedure to clearly identify road and rail network (code 12200) and its sub-classes. To disengage class other roads and associated land (code 12220) from other classes, "elliptic fit", "border length", "shape index", "brightness" and "asymmetry" functions were applied to SPOT-5 images and road and rail networks were classified. Besides, to distinguish roads between the agricultural areas, NDVI and brightness values were used. NDVI values, soil sealing layer, standard deviation and brightness values in NIR band were used to identify artificial surfaces. Human influence is dominant on artificial surfaces except agricultural use. Built-up areas, roads, infrastructure constructions and other artificially sealed areas are example for artificial surface class. ${ }^{16}$ Different threshold values were applied to soil sealing layer as illustrated in Urban Atlas mapping guide to accurately map class 11100 , 11200 and sub-classes of 11200 . To identify continuous urban fabric (11100), objects in urban classes having $80 \%$ or bigger values for soil sealing were selected. This class mostly includes buildings, road and paved areas. As can be seen in Figure 6 and 7, Gaziantep city center is mostly covered by this class. Discontinuous urban fabric (11200) was classified using urban class and soil sealing values between $10 \%$ and $80 \%$. Sub-classes of discontinuous urban fabric are 11210 with sealing layer value of $50-80 \%, 11220$ with sealing layer value of $30-50 \%$ and 11230 with sealing layer value of $10-30 \%$ and 11240 with sealing layer value of $0-10 \%$.

After the classification of 6 regions with similar rulesets, city center (Region 7) of Gaziantep was classified with an additional dataset; master zoning maps. Master zoning maps were incorporated in the segmentation process which then was used to assign artificial surface classes such as $12100,12230,14100$ etc.

At the last step, a confusion matrix was created using reference points distributed randomly to check the accuracy of the proposed methodology. Overall accuracy, user's and producer's accuracies of each class were calculated and the results were analyzed to find out the performance of current approach.

\section{Results and Discussion}

Current urban land cover/use map (Urban Atlas) of Gaziantep city with the total area of $6,558 \mathrm{~km}^{2}$ was created by using object based classification of high resolution SPOT-5 images with the aid of other data sources. Different decision tree algorithms were developed in this research to accurately map different urban classes. Results of the study showed that most of the urban classes were classified with $90 \%$ or more user's and producer's accuracies.

SPOT-5 images itself are not solely enough to map urban classes used in this research considering that some of them are related to land use. However, integration of different thematic layers into the classification procedure significantly improved the classification results and helped to produce several urban land cover and use classes.

After conducting the classification, it was found that water areas are occupied $1 \%$ of the city with a total area of $60 \mathrm{~km}^{2}$. Percentage of urban areas are $5 \%$ with a total area of $291 \mathrm{~km}^{2}$ including continuous urban fabric and three different discontinuous urban fabrics with different densities. Urban density map could be created based on these classes. Forest area covers $9 \%\left(616 \mathrm{~km}^{2}\right)$ and agricultural area, semi-natural areas and wetlands cover 5,591 $\mathrm{km} 2$ with the highest percentage of $85 \%$. Gaziantep urban land cover/use map is presented in Figure 5. Total area of water, urban and forest area cover lower proportion compared to agricultural, semi-natural and wetland areas.

Land cover/use classes used in this research adapted from Urban Atlas project and these 
classes could provide valuable information for different applications in city scale for different levels of users from public to decision makers and city planners. For example, transportation classes (code 12210-12230) could be used for route mapping, shortest distance calculation and emergency planning. Green urban areas class (code 14100) can be used to find out extent and spatial distribution of green areas which serves as a meeting place and support social contacts in daily life and this information could be used for further planning these areas.
Figure 6 illustrates the urban map of the city center. Mostly, urban sprawl could be seen in radial direction around the city center of Gaziantep and in some parts linear direction along the highways.

Classification results were converted into vector format and 634,671 polygons were created to represent different classes of Gaziantep urban land use/map.
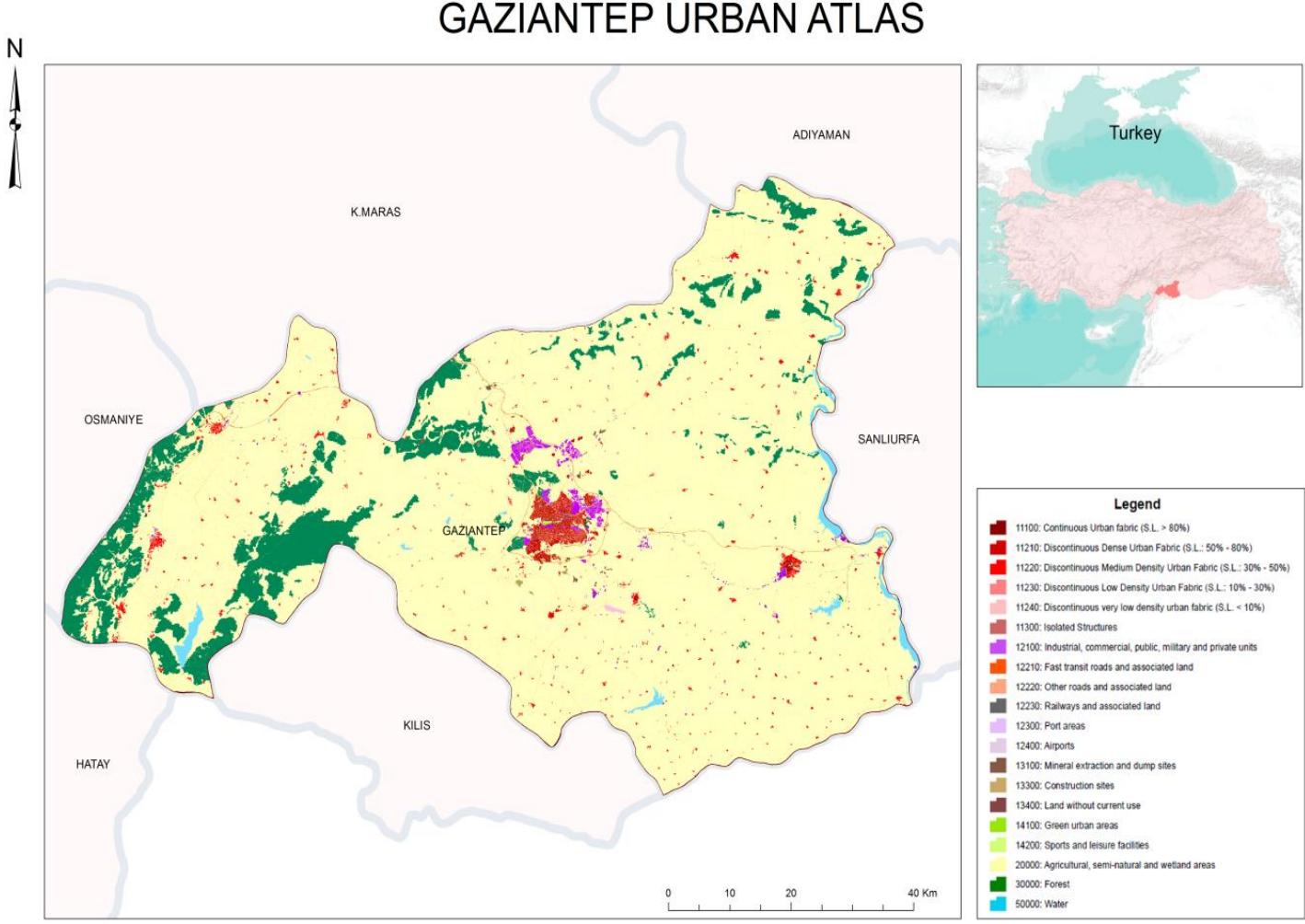

Fig. 5 Gaziantep urban land cover/use map 


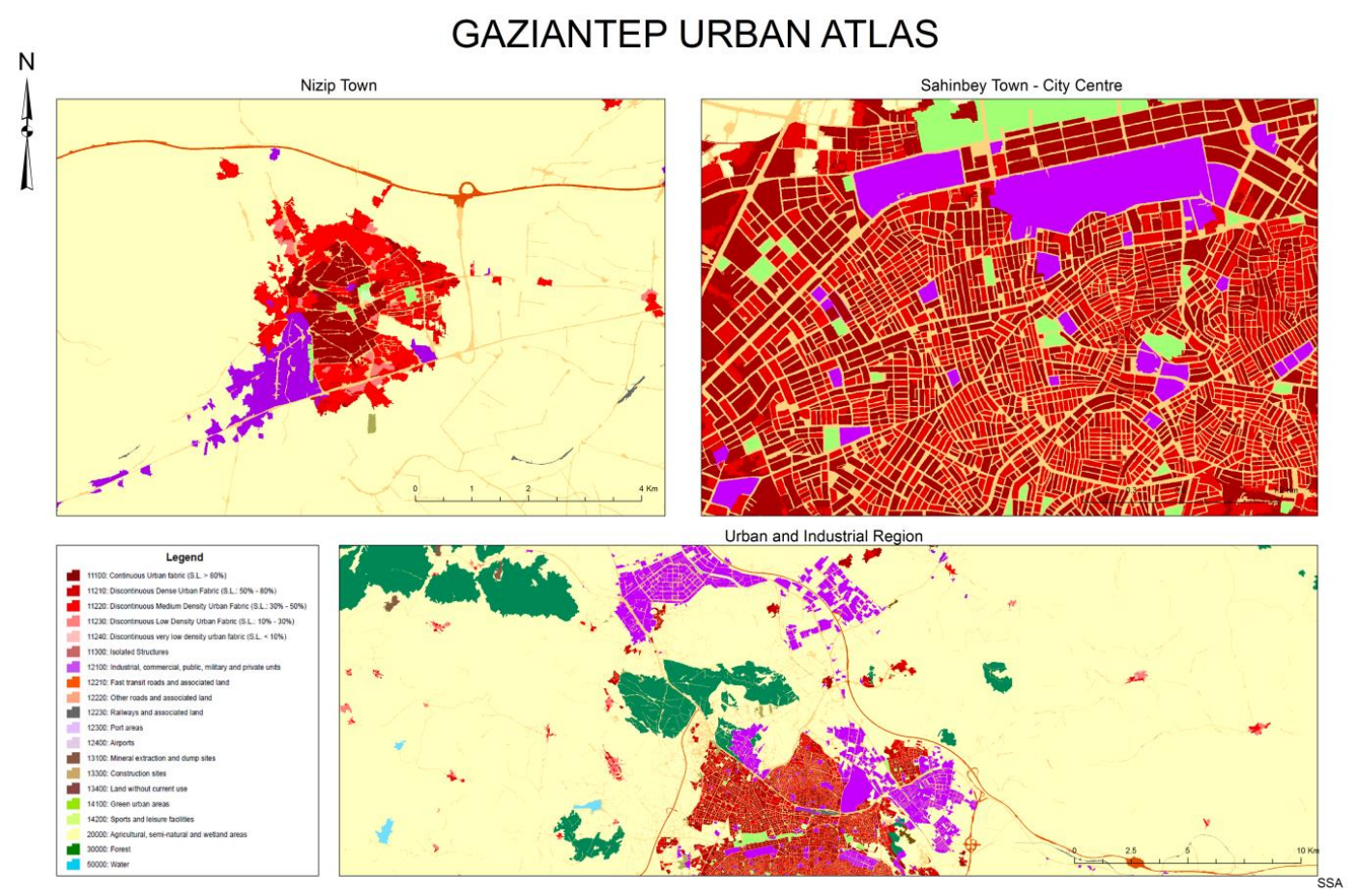

Fig. 6 City center map of Gaziantep city

Table 4 Results of the accuracy assessment for each class

\begin{tabular}{|l|l|l|l|}
\hline $\begin{array}{l}\text { Class } \\
\text { Code }\end{array}$ & Class Name & $\begin{array}{l}\text { Producer's } \\
\text { Accuracy }\end{array}$ & $\begin{array}{l}\text { User' } \\
\text { Accuracy }\end{array}$ \\
\hline 10000 & Artificial Surfaces & 94.86 & 99.59 \\
\hline 11000 & Urban Fabric & 93.53 & 97.66 \\
\hline 12100 & Industrial, Commercial, Public, Military and Private Units & 96.83 & 95.31 \\
\hline 12200 & Road And Rail Network and Associated Land & 87.87 & 98.35 \\
\hline 12400 & Airports & 90.00 & 100.00 \\
\hline 13100 & Mineral Extraction And Dump Sites & 100.00 & 96.83 \\
\hline 13300 & Construction Sites & 91.55 & 100.00 \\
\hline 14100 & Green Urban Areas & 94.87 & 100.00 \\
\hline 14200 & Sports And Leisure Facilities & 97.06 & 100.00 \\
\hline 20000 & Agricultural, Semi-Natural and Wetland Areas & 98.22 & 84.26 \\
\hline 30000 & Forest & 95.00 & 96.38 \\
\hline 50000 & Water & 95.77 & 100.00 \\
\hline
\end{tabular}




\section{Accuracy Assessment}

Total of 1,564 points were used for the accuracy assessment. Coordinates and land cover/use class information of these points were determined from higher resolution satellite images like SPOT-6, Worldview and from 1:1,000 scale master zoning maps. According to assessment results, overall accuracy of the classification is $94.31 \%$ with a kappa value of 0.932 . Overall accuracy for urban areas is 95.46 $\%$ with a kappa value of 0.919 ; whereas overall accuracy of rural areas is $95.20 \%$ with a kappa value of 0.935 . The following table summarizes producer's and user's accuracies of each class.

Most of the classes have $90 \%$ or better both user's and producer's accuracies. Agricultural, Semi-Natural and Wetland Areas were mixed with urban fabric and road related classes in some parts of the study region causing $84.26 \%$ user's accuracy for agricultural, semi-natural and wetlands class.

\section{Conclusions}

SPOT-5 images in conjunction with other ancillary data could be successfully used to create detailed urban land use/cover maps of large areas. Integration of different thematic layers such as CORINE land cover, cadastral maps, Openstreetmaps, NDVI and NDWI index maps into the segmentation process and classification algorithm via creating new decision trees has significantly improved the results of this research. High resolution urban map created in this research could be used as the core urban information source for city planners, municipalities and related governmental agencies acting as decision makers for development and management of urban areas and implementation of urban policies.

This research concentrated of creation of current single dated urban map. Nevertheless, multi-temporal high resolution urban maps could be created following the proposed approach to find out the landscape changes of urban classes within specific time periods. This information could also help to monitor urban sprawl, to better understand landscape and to support decision-makers on city and regional planning for sustainable solutions for landscape change. Detection of changes such as unauthorized construction would be possible by using multi-temporal urban atlas maps.

Density of residential areas, commercial and industrial zones in a city could be easily derived using the related classes in the created urban map. Moreover, high resolution urban map created in this study could be used to support master planning, monitor transportation infrastructures, generate location based services and support of street navigation.

There are several urban atlas maps available for different European cities based on the classification scheme which was also used in this study. This provides opportunity for the intercomparison of different European cities or other cities created base on this classification scheme like our case.

\section{Acknowledgments}

Elif Sertel conceived and designed the framework of the study. Semih Sami Akay conducted image processing. Analysis and interpretation of results and manuscript writing were fullfilled by Elif Sertel and Semih Sami Akay. We would like to thank Center for Satellite Communication and Remote Sensing of Istanbul Technical University for providing SPOT-5 data set and Irmak Yay Algan (MSc) for her generous support.

\section{References}

Akay, S. S. "A Case Study for Urban Atlas Project: Gaziantep City," Master Thesis, Istanbul Technical University, Istanbul (2014).

Blaschke, T., G. J. Hay, Q. Weng, and B. Resch, "Collective Sensing: Integrating Geospatial Technologies to Understand Urban Systems," An Overview, Remote Sensing 3(8), 1743-1776 (2011).

Campbell, J. Introduction to Remote Sensing, 4th ed., The Guilford Press, New York (2007).

City Development Information. Available online: http://tr.wikipedia.org/wiki/ (accessed on 14 October 2014) 
City Population. Available online: http://www.tuik.gov.tr/PreTablo.do?alt_id= 1059, (accessed on 20 April 2014).

Deng, J.S. K. Wang, Y. Hong, and J. G. Qi, "Spatio-Temporal Dynamics and Evolution of Land Use Change and Landscape Pattern in Response to Rapid Urbanization," Landscape and Urban Planning 92(3-4), 187-198 (2009).

eCognition, eCognition Developer (8.64.0) Reference Book, Trimble Germany $\mathrm{GmbH}$, Munich, (2010).

Gamba, P. F. Dell'Acqua, and B. Dasarathy, "Urban Remote Sensing Using Multiple Datasets: Past, Present, And Future," Information Fusion 6, 319-326 (2005).

Herold, H., M. E. Gardner, and D. A. Roberts, "Spectral Resolution Requirements for Mapping Urban Areas," IEEE Transactions on Geoscience and Remote Sensing 41(9), 1907-1919 (2003).

Lobo, A. "Image Segmentation and Discriminant Analysis for The Identification of Land Cover Units in Ecology," IEEE Transactions on Geoscience and Remote Sensing 33, 1136-1145 (1997).

Lu, D. and Q. Weng, "Use of Impervious Surface in Urban Land-use Classification," Remote Sensing of Environment 102(1-2), 146-160 (2006).

Ludlow, D. and W. Steinborn, "The European Urban Atlas," Towards eEnvironment Conference, Prague (2009).

Mapping Guide for a European Urban Atlas, European Environmental Agency web page. Available online: http://ec.europa.eu/regional_policy/tender/p df/2012066/annexe2.pdf (accessed on 29 April 2014)

Matikainen, L. and K. Karila, "Segment-Based Land Cover Mapping of A Suburban Area-Comparison of High-Resolution Remotely Sensed Datasets Using Classification Trees and Test Field Points," Remote Sensing 3, 1777-1804 (2011).

Mohapatra, R. P. and C. Wu, "High Resolution Impervious Surface Estimation: An
Integration of IKONOS and Landsat-7 ETM+ Imagery," Photogrammetric Engineering and Remote Sensing 76, 13291341 (2010).

Myint, S.W., P. Gober, A. Brazel, S. G. Clark, and Q. Weng, "Per-Pixel vs. Object-Based Classification of Urban Land Cover Extraction Using High Spatial Resolution Imagery," Remote Sensing Environment, 115(5), 1145-1161 (2011).

Salehi, B., Y. Zhang, M. Zhong, and V. Dey, "Object-Based Classification of Urban Areas Using VHR Imagery and Height Points Ancillary Data," Remote Sensing, 2072-4292 (2012).

Seifert, F. M. "Global Mapping of Human Settlement: Experiences, Datasets and Prospects," Chapter 11: Improving Urban Monitoring Toward a European Urban Atlas, Taylor and Francis Group, Boca Raton, FL (2009).

Sertel, E., N. Findik, S. Kaya, D. Z. Seker, and A. Samsunlu, "Assessment of Landscape Changes in the Kizilirmak Delta, Turkey Using Remotely Sensed Data and GIS," Environmental Engineering Science 25(3), 353-362 (2008).

Thapa, R. B. and Y. Murayama, "Urban Mapping, Accuracy and Image Classification: A Comparison of Multiple Approaches in Tsukuba City, Japan," Applied Geography 29, 135-144 (2009).

Thomas, N., C. Hendrix and R. Congalton. "A comparison of urban mapping methods using high-resolution digital imagery", Photogrammetric Engineering \& Remote Sensing, 69(9), 963-972 (2003).

Urban Atlas Final Report. Urban Atlas Delivery of Land Use/Cover Maps of Major European Urban Agglomerations. Available online:

http://ec.europa.eu/regional_policy/tender/p df/ 2012066/urban_atlas_final_report_112011. pdf (accessed on 29 April 2014)

Walker, J. S. and T. Blaschke, "Object- Based Land- Cover Classification for the Phoenix Metropolitan Area: Optimization vs. 
Transportability," International Journal of

Remote Sensing 29(7), 2021-2040 (2008).

Weng, Q. "Remote Sensing of Impervious

Surfaces in The Urban Areas:

Requirements, Methods, and Trends,"

Remote Sensing of Environment 117, 34-49

(2012). 